\title{
Zur Resistenz von Blaualgen gegen kurzwellige Strahlung
}

\author{
Von Alfons Zehnder und Beatrix Egli \\ Eidg. Anstalt für Wasserversorgung, Abwasserreinigung und Gewässerschutz (EAWAG), \\ $\mathrm{CH}-8600$ Dübendorf
}

Manuskript eingegangen am 25. Januar 1978

\section{Einleitung und Ziel}

Die Herstellung axenischer Klonkulturen von Blaualgen ist zwar in neuerer Zeit auf verschiedenen Wegen gelungen $[1,4,5,22,24,25$ u. a.], ist aber bei vielen Formen nach wie vor mühsam und schwierig. So versagen aus traditioneller bakteriologischer Isolationstechnik hergeleitete Verfahren oft bei Arten mit gelatinösen Hüllen oder Scheiden, die von Bakterien besiedelt sind. Auch die seit etwa 1950 zur Elimination von Bakterien oft eingesetzten UV-Strahlen [9 u. a.] führen nicht immer zum Ziel [12].

Kraus [17] behandelte Cyanophytenkulturen mit Gammastrahlen und erhielt so 17 axenische Stämme: Die Algen waren resistenter als ihre Begleitbakterien und überlebten diese. Von Misserfolgen berichtet Kraus nicht. Später fand Asato [3] bei Anacystis nidulans hohe Gammastrahlentoleranz.

Die vorliegende Studie soll einen Hinweis geben, ob bei Blaualgen a) eine Beziehung zwischen taxonomischer Stellung und Strahlentoleranz und/oder b) eine Beziehung zwischen ökologischem Verhalten und Strahlentoleranz bestehe. Dahinter stand die Frage, ob sich bei einem bestimmten Blaualgentaxon mit einiger Wahrscheinlichkeit voraussagen lasse, ob eine Behandlung mit Gamma- oder UVStrahlen zu axenischen Kulturen führen werde.

\section{Material und Methoden}

\subsection{Algen}

Die 13 untersuchten Cyanophyten sind in der Tabelle Seite 172 zusammengestellt. Abgesehen von Synechococcus elongatus wurden alle Stämme von den Autoren aus Naturmaterialien genau bekannter geographischer (Fundort) und ökologischer (Standort) Herkunft isoliert und in die Algenkulturensammlung der Eidg. Anstalt für Wasserversorgung, Abwasserreinigung und Gewässerschutz (EAWAG) übergeführt [28], wo sie als Standkulturen in der Nährlösung $Z$ [25] unter den in der Tabelle angegebenen Nummern gehalten werden. Der Arbeitsablauf von der Gewinnung des Naturmaterials bis zur Überführung in die Algothek wird für jeden Klon in einer Isolierungsgeschichte (Signatur mit drei Buchstaben, zum Beispiel PVE) archiviert. 
Die taxonomische Bezeichnung einiger Stämme ist provisorisch; ob zum Beispiel Klon 100a Scytonema myochrous (Dillw.) Born. oder S.mirabile (Dillw.) Born. heissen soll, ob Scytonema lvngbvoides Gardner richtig bestimmt ist, bleibt vorderhand unsicher, soll aber in diesem Zusammenhang nicht diskutiert werden.

Synechococcus elongatus Näg., EAWAG Nr.8, ist der von Pringsheim isolierte Klon Cambridge LB 1479/1. Die Ökologie ist schlecht bekannt. Die Angabe Geitlers [8] "auf feuchter Erde, am Grund alter Baumstämme ...», das Fehlen in Golubics [10] und Jaags [13] Listen und der Hinweis Desikacharis [6] "on submerged rocks in a lake ...) lassen auf eine Schattenform schliessen, die sowohl aerophytisch als auch untergetaucht gedeiht. In Kultur entwickelt sie sich in flüssigem Milieu (Nährlösung Z) und auf Agarböden gut.

Microcystis flos-aquae (Wittr.) Kirchn., EAWAG Nrn.98 und 198a, Isolierungsgeschichten MRO bzw. MGR.

Herkunft: Stamm Nr.98 wurde im September 1963 aus einer Wasserblüte des Rotsees bei Luzern isoliert. Aus unbekannten Gründen ging er 1972 ein. Eine Wiederholung des Gammastrahlenversuches und die UV-Bestrahlung erfolgten daher mit Stamm Nr.198a, der im September 1971 aus einer Wasserblüte im Greifensee (Kt. Zürich) isoliert worden war.

Ökologie: In eutrophen Seen und Teichen weltweit verbreiteter Plankter.

Chroococcus minor (Kütz.) Näg., EAWAG Nr. 129, Isolierungsgeschichte GBE.

Herkunft: Berninapass, Schweiz, LK: Koord. 799400/141200, $2230 \mathrm{~m}$ ü. M., am Weg zum Sassal Masone.

Ökologie: Die Art wurde von Golubić [10] «submers, im Seelitoral, schattig» festgestellt. Nach Geitler [8] ist sie wenig wählerisch: «... in stehendem Wasser, an feuchten Felsen, Mauern und dgl.» Der vorliegende Klon wurde im Sommer 1965 aus einem Material isoliert, das zur Hauptsache Gloeocapsa sanguinea enthielt und das an einer von dünnem Wasserfilm überrieselten vertikalen. südexponierten kleinen Gneisstufe gesammelt worden war. Die Stelle war vollem Tageslicht ausgesetzt.

Chamaesiphon polonicus (Rostaf.) Hansg., EAWAG Nr.118a, Isolierungsgeschichte CAS.

Herkunft: Aus einem von Gloeocapsa sanguinea dominierten Artengemisch, das im Januar 1965 von einer überrieselten Kalkfelswand bei Stansstad am Vierwaldstättersee abgekratzt wurde.

Ökologie: Kann, welche die Art systematisch [14] und ökologisch [15] studierte, nennt sie «hauptsächlich eine Art des Fliesswassers», die aber auch im Eulitoral von Seen vorkomme. Sie ertrage Austrocknung, trete daher auch auf nur zeitweise überrieselten Felsen auf, sei zudem eurytherm (dies im Gegensatz zu Geitler [8], der sie als oligo- und stenotherm bezeichnet). Geitler, für den sie vorerst eine Bewohnerin von Steinen im Bett schnellfliessender Gebirgsbäche ist, betont ihre Fähigkeit, längere Trockenzeiten zu überdauern; ja nach ihm gehört die Art «zu den extremen Trockenformen» ([8], S. 436). Jaag [13] schliesslich findet sie unter den Erstbesiedlern von durch Schneeschmelzwasser überrieselten, vollem Tageslicht ausgesetzten 
Felswänden im Gebiet des Morteratschgletschers und am Rhonegletscher, also extremer Sonnenstrahlung ausgesetzt.

Tolypothrix penicillata Thuret., EAWAG Nr.96b, Isolierungsgeschichte TKA. Herkunft: Vierwaldstättersee. Im Oktober $196350 \mathrm{~m}$ südlich vom Hydrobiologischen Laboratorium, Kastanienbaum, von der Ufermauer in der unteren Wellenschlagzone gewonnen.

Ökologie: Golubić [10] findet sie im Seelitoral in der Nähe des Wasserspiegels; Geitler [8] erwähnt schnellfliessende Gewässer und die Wellenschlagzone von Bächen und Teichen als Standorte. Doch tritt sie auch in Rieselwasserstreifen an Felswänden, zum Beispiel neben dem Staubbachfall im Lauterbrunnental, auf. Jaag stellt sie, wenn auch sehr spärlich, auf Granit unterhalb der Bovalhütte im Kanton Graubünden auf $2350 \mathrm{~m}$ ü. M. in Südostexposition, also in einem extremen Strahlungsklima, fest, an einer Stelle, an der «durch das ganze Jahr mehr oder weniger gleich lange Perioden der Benetzung und der Trockenheit aufeinander folgen» ([13], S.246).

Scytonema myochrous (Dillw.) Ag. emend. Jaag, EAWAG Nr. 100a, Isolierungsgeschichte SHR.

Herkunft: Hauterive, Kt. Freiburg, Schweiz, LK: Koord. 575 100/179 400. Strähnige Fadenbüschel an der südexponierten, den Lauf der Saane flankierenden Molassefelswand, die an der Fundstelle von einem Wasserfilm überflossen wird. Volles Tageslicht, wobei der Fluss zusätzlich Licht an die Wand reflektiert. April 1964.

Ökologie: Es sei auf Jaag [13] verwiesen, dem sich auch Golubić [10] anschliesst: Scytonema myochrous besiedelt Felsen verschiedenster Benetzungsstufen und toleriert volles Tageslicht.

Scytonema burmanicum Skuja, EAWAG Nr. 154a, Isolierungsgeschichte CEM.

Herkunft: Nepal, Katmandu, Chet Bhawan, April 1968. Schwarze, filzig aussehende, nach dem fast niederschlagslosen Winterhalbjahr völlig ausgetrocknete Pelzchen von unregelmässiger Form und bis etwa $0,5 \mathrm{~cm}^{2}$ messend, werden von einer vertikalen, etwa nordwestexponierten Backsteinmauerfläche gekratzt. Das Material besteht fast ausschliesslich aus Scytonema burmanicum.

Ökologie: Skuja [23] beschreibt die Art aufgrund zweier ihm zugesandter fixierter Proben aus Burma und nennt sie, vermutlich die Beschriftung der Proben zitierend, «aerophytic on trees ...» Desikachari übernimmt das Taxon von Skuja, ohne weitere Fundorte oder eigene ökologische Befunde beizufügen. Der Standort des vorliegenden Materials ist vollem Tageslicht ausgesetzt. Direkte Sonnenstrahlen fallen aber erst am Spätnachmittag auf. Ausgesprochener Aerophytenstandort.

Scytonema lyngbyoides Gardner, EAWAG Nr.159d, Isolierungsgeschichte SFP. Herkunft: Nepal, Pokhara, $800 \mathrm{~m}$ ü. M., Dezember 1967. Ein hausgrosser, isoliert auf einer ebenen Wiese beim Prithuri Narayan College liegender nackter Granitblock trägt auf seinen senkrechten Seitenflächen verschiedenartige Algenbeläge. Auf der Südseite fällt ein ausgedehnter, braunroter, samtartiger Pelz auf, der fast ausschliesslich aus Porphyrosiphon Notarisii besteht. Daneben haften auf der 
Granitfläche braunschwarze Pusteln von bis etwa $3 \mathrm{~mm}$ Durchmesser. Sie grenzen oft so eng aneinander, dass sich eine fast zusammenhängende rissige, olivbraune bis schwarze Kruste von bis $3 \mathrm{~mm}$ Dicke ergibt. Die mikroskopische Analyse zeigt, dass dieses Material zu wohl über $95 \%$ aus einem Stigonema besteht. Vereinzelt sind damit Scytonemataceen und Chroococcalen vermischt. Während Stigonema in vitro trotz wiederholten Ansätzen nicht wuchs, konnten aus dem Naturmaterial ein Chroococcus, eine Tolypothrix und zwei Scytonema-Arten, darunter der vorläufig als Scytonema lyngbyoides Gardner bezeichnete Klon $159 \mathrm{~d}$, isoliert und kultiviert werden.

Ökologie: Geitler [8] basiert offenbar auf Gardner: «Auf Felsen, Porto Rico.» Desikachari [6] erwähnt die Art nicht. Die Stelle in Pokhara erlaubt nur Formen ein Aufkommen, die extreme Austrocknung und volles Tageslicht ertragen.

Aphanizomenon flos-aquae (L.) Ralfs, EAWAG Nr. 103, Isolierungsgeschichte AGR. Herkunft: Wasserblüte im Greifensee, Kt. Zürich, November 1963.

Ökologie: Plankter, in eutrophen Seen Europas und Nordamerikas oft Wasserblüten bildend. In schweizerischen Seen vereinzelt seit längerer Zeit nachweisbar (im Pfäffikersee zum Beispiel seit 1941 [19]), seit etwa 1960 auch Wasserblüten bildend, so im Neuenburgersee zum erstenmal 1961, im Pfäffiker- und Greifensee 1961 [19], im Murtensee 1963 (H. Roggen, Apotheker, Murten, in lit.).

Anabaena flos-aquae (Lyngb.) Bréb., EAWAG Nr.116a, Isolierungsgeschichte AHF

Herkunft: Aus einer Wasserblüte im Hallwilersee, Schweiz, Oktober 1965.

Ökologie: Kosmopolitischer, häufiger Plankter in Seen mit kalkhaltigem Wasser. Bildet Wasserblüten, oft gemeinsam mit Microcystis aeruginosa und Gloeotrichia echinulata [21].

Anabaena planctonica Brunnth., EAWAG Nr. 115b, Isolierungsgeschichte AHP. Herkunft: Hallwilersee, Oktober 1965. Aus der gleichen Wasserblüte isoliert wie Anabaena flos-aquae, Nr. 116 a.

Ökologie: Plankter in Seen Europas, Kleinasiens, Nordamerikas [8, 21].

Phormidium autumnale (Ag.) Gom., EAWAG Nr.99a, Isolierungsgeschichte PVE. Herkunft: Verzascatal, Kt. Tessin, Schweiz, Juli 1964. Etwas unterhalb der Staumauer des Lago di Vogorno rinnt neben der neuen Strasse ein Bächlein eine kleine Felsmulde herab. Es riecht (1964) deutlich nach häuslichem Abwasser, das offenbar aus einer temporären Arbeiterunterkunft auf einem Plateau über der Strasse stammt. Beide Seiten des vollem Tageslicht exponierten Bächleins werden von auffälligen, handbreiten, glänzendschwarzen Streifen begleitet: Phormidium autumnale in Massenentwicklung. (Makroskopisch ähnlich aussehende Beläge wurden zum Beispiel im Sommer 1963 in der Nähe einer Lampe im Inneren der Beatushöhlen am Brienzersee beobachtet. Dieses Material wurde als Phormidium ambiguum Gom. bestimmt [27].) Einzelne Fäden liessen sich leicht isolieren und wuchsen in Nährlösung Z [25] ohne Schwierigkeiten zu Klonkulturen heran.

Ökologie: Geitler nennt als Standorte «feuchte, verschmutzte Erde, an Mauern, Baumstämmen, seltener in Bächen» ([8], S. 1026). Golubić [10] verweist auf die 
Bestimmungsschwierigkeiten und in Zusammenhang damit auf die Tatsache, dass die Art in neuerer Zeit öfters aus fliessenden Gewässern angegeben wird. Vielleicht versteckt sich dahinter ein Wandel in der Umschreibung dieser schwierig zu fassenden Art; vielleicht ist der häufigere Nachweis in Fliessgewässern aber auch Ausdruck ihrer Abwasserbelastung. Prescott [21] gibt keine ökologischen Hinweise. Der Standort im Verzascatal ist vollem Tageslicht ausgesetzt.

\subsection{Bestrahlung}

\subsection{Gammastrahlen}

Die ausgewählten Stämme wurden als Standkulturen angezogen (200-ml-Erlenmeyerkolben mit je $100 \mathrm{ml}$ Medium Z, $20^{\circ} \mathrm{C}$, Fluoreszenzlicht Philips White, 500-1000 Lux, $12 \mathrm{~h} / \mathrm{d}$ ). Kräftig wachsendes Kulturmaterial wurde samt $10 \mathrm{ml}$ Medium in bakteriologische Kulturröhrchen übertragen und zur Bestrahlung in das Eidgenössische Institut für Reaktorforschung (EIR) in Würenlingen gebracht. Als Strahlenquelle diente ${ }^{60} \mathrm{Co}$ der "Gammacell-220» (Atomic Energy of Canada Ltd.). Bei der ersten Bestrahlungsserie, die 9 Klone umfasste, betrug ihre Energiedosisleistung 422 krad pro Stunde. Die Wahl der Energiedosen basierten wir auf Kraus [17] sowie Morton und Derse [20], das heisst, von jedem Algenklon wurde je eine Probe mit 30, $65,130,260,520,1000,1500,2000,2500 \mathrm{krad}$ behandelt, was zu Expositionszeiten von etwa 5 Minuten bis 6 Stunden führte. Die restlichen Klone (Tabelle) wurden 4 Jahre später bestrahlt. Wegen der inzwischen verminderten Energiedosisleistung der Strahlenquelle waren die zur Erzielung der gleichen Energiedosen erforderlichen Expositionszeiten höher.

Aus jeder bestrahlten Probe wurde Material in Kulturkolben mit Nährlösung Z zur Feststellung des Algenwachstums und weiteres Material in Röhrchen mit dem Bakteriennährboden Trypton-Glukose-Extrakt-Agar (Difco) zu einer Grobprüfung auf lebende Bakterien übertragen. Bei positivem Ausgang des Algenwachstumsund negativem Ausgang des ersten Bakterientests wurde nach einigen Wochen Material aus wachsenden Algensubkulturen auf Malzagar, Nährgelatine, Thioglycolat-Medium und Trypton-Glukose-Extrakt-Agar (alles Difco) übertragen und vorerst 2 Wochen bei $20^{\circ} \mathrm{C}$, darauf 1 Woche bei $35^{\circ} \mathrm{C}$ und bei weiterhin negativem Befund weitere 4 Wochen im Dunkeln bei Zimmertemperatur aufbewahrt.

Die so axenisch befundenen Algenkulturen wurden nach mehrwöchiger Inkubation mikroskopisch auf Bakterien durchsucht. Erfahrungsgemäss [24] lassen sich so Bakterien in alten Kulturen leicht nachweisen.

\subsection{UV-Strahlen}

Suspensionen von Algenkulturen in vollem Wachstum wurden in einer sterilen Kammer in Petrischalen so verteilt, dass die Mediumschicht etwa $3 \mathrm{~mm}$ hoch stand. Sie wurden unbedeckt dem Licht einer UV-Fluoreszenzröhre (Philips 57413/40f. UV 30 Watt) in $40 \mathrm{~cm}$ Distanz ausgesetzt. Nach 2, 4, 8, 16, 32, 64, 128 und 256 Minuten wurden Proben aus den Petrischalen in Kulturkolben pipettiert und 
inkubiert. Die Weiterbehandlung und die Prüfung auf Bakterien erfolgten gleich wie nach der Behandlung mit Gammastrahlen.

\section{Resultate und Diskussion}

Die Resultate sind in der Tabelle zusammengefasst.

Gamma- und UV-Strahlentoleranz einiger Cyanophyten (Kulturen aus der Sammlung der EAWAG. Dübendorf. Schweiz).

Tolerance of some blue-green algae to gamma and UV radiation.

\begin{tabular}{|c|c|c|c|c|c|c|c|}
\hline $\begin{array}{l}\text { Klon } \\
\text { EAWAG } \\
\mathrm{Nr}\end{array}$ & Taxonomic & $\begin{array}{l}\text { Öko- } \\
\left.\operatorname{logie}^{1}\right)\end{array}$ & $\begin{array}{l}\text { Toleran } \\
\text { Serie }^{2} \text { ) }\end{array}$ & $\begin{array}{r}\text { Gamma- } \\
\text { strahlen } \\
\text { krad }\end{array}$ & $\begin{array}{l}\text { Kultu- } \\
\text { ren }^{3} \text { ) }\end{array}$ & $\begin{array}{r}\text { UV- } \\
\text { Strahlen } \\
\text { min }\end{array}$ & $\begin{array}{r}\text { Kultu- } \\
\left.\text { ren }^{3}\right)\end{array}$ \\
\hline & Chroococcales & & & & & & \\
\hline 8 & Sunechococcus elongatus & A, Sch? & 1 & 65 & b & 32 & $b$ \\
\hline 98 & Microcvstis flos-aquae & $\mathrm{P}$ & 1 & 260 & $b$ & - & - \\
\hline $198 \mathrm{a}$ & Microcystis' flos-aquae & $\mathrm{P}$ & 2 & 65 & $b$ & 32 & $\mathrm{~b}$ \\
\hline 129 & $\begin{array}{l}\text { Chroococcus minor } \\
\text { Chamaesiphonales }\end{array}$ & $\mathrm{Li}, \mathrm{Lp}, \mathrm{T}$ & 1 & 1000 & a & 16 & $b$ \\
\hline $118 a$ & $\begin{array}{l}\text { Chamaesiphon polonicus } \\
\text { Nostocales } \\
\text { Scytonemataceae }\end{array}$ & $\mathrm{F}, \mathrm{Lp}, \mathrm{T}$ & 1 & $>2500$ & a & $>256$ & b \\
\hline $96 \mathrm{~b}$ & Tolypothrix penicillata & Li, Lp & 1 & 1500 & a & $>256$ & $b$ \\
\hline $100 a$ & Scytonema mvochrous & Lp, T & 1 & 1500 & a & $>256$ & $b$ \\
\hline $154 a$ & Scylonema burmanicum & A & 2 & $>2500$ & a & $>256$ & b \\
\hline $159 \mathrm{~d}$ & $\begin{array}{l}\text { Scytonema lyngbvoides } \\
\text { Nostocaceae }\end{array}$ & $A, L p$ & 2 & 1500 & a & $>256$ & $\mathrm{~b}$ \\
\hline 103 & A phanizomenon flos aquae & $\mathrm{p}$ & 1,2 & 130 & $b$ & 2 & $b$ \\
\hline $116 \mathrm{a}$ & A nabaena flos-aquae & $\mathrm{P}$ & 1 & 65 & $b$ & $>256$ & $b$ \\
\hline $115 b$ & $\begin{array}{c}\text { Anabaena planctonica } \\
\text { Oscillatoriaceae }\end{array}$ & $\mathrm{P}$ & 2 & 65 & $b$ & 32 & $\mathrm{~b}$ \\
\hline $99 \mathrm{a}$ & Phormidium autumnale & A, F, Li & 1 & 1500 & a & $>256$ & a \\
\hline
\end{tabular}

1) Ökologie: $A=$ Aerophyt, $F=$ Fliesswasserform, $\mathrm{Li}=$ Litoralform, $\mathrm{Lp}=$ Lithophyt, $\mathrm{P}=$ Plankter, Sch $=$ Schattenform, $\mathrm{T}=$ in Tintenstrichen.

2) Serie: $1=$ Bestrahlungen $1970,2=$ Bestrahlungen 1974.

3) Kulturen: $a=$ Algenkultur nach Bestrahlung axenisch, $b=$ Algenkultur nach Bestrahlung bakterienhaltig.

\subsection{Gammastrahlen}

Die Gammastrahlentoleranz der Blaualgen zeigt eine weite Amplitude: Bei Planktern gleich welcher taxonomischen Stellung ist sie niedrig: So tolerierten Klon 198a der Kolonien bildenden Microcystis (Chroococcales) sowie Anabaena planctonica und A.flos-aquae (Hormogonales) nur je $65 \mathrm{krad}$. Da Begleitbakterien bei allen Planktern höhere Strahlendosen ertrugen, liessen sich auf diesem Wege keine axenischen Kulturen planktischer Blaualgen erzielen. Die Bakterientests unmittelbar nach der Bestrahlung zeigten immerhin eine starke Reduktion der Keimzahl, verglichen mit jener unbestrahlter Parallelkulturen. Lange [18] machte analoge Erfahrungen mit einem weiteren Plankter. Gloeotrichia echinulata: ${ }^{60} \mathrm{Co}$ gamma 
radiation killed the alga prior to the bacteria so that no axenic culture could be obtained by this method.'

Ganz anders verhielten sich Lithophyten: Chamaesiphon polonicus, von Jaag [13], wie weiter oben dargelegt, als Erstbesiedler überrieselter Felswände in extremem Strahlungsklima nachgewiesen, und Scytonema burmanicum, über dessen Ökologie freilich wenig bekannt ist, wurden durch eine im Verlauf von rund 6 Stunden eingestrahlte Energiedosis von $2500 \mathrm{krad}$ nicht abgetötet. Auch die übrigen Arten, welche bei unserer Versuchsanordnung eine Gammastrahlendosis von 1000 oder mehr krad tolerierten, treten als Lithophyten-Aerophyten in der Natur oft an Standorten mit intensiver Sonnenbestrahlung auf. Die Begleitbakterien aller dieser Arten zeigten sich weniger resistent. Sie wurden abgetötet, und die Bestrahlung führte damit zu axenischen Algenkulturen.

Auffallenderweise fehlen unter den geprüften Stämmen Arten mit einer mittleren Toleranz: Wenn man vom leider eingegangenen Microcystisklon Nr.98 absieht, besteht eine Lücke zwischen den kaum 100 krads ertragenden Planktern und den 1000 oder mehr krad ertragenden Lithophyten. Ob sich bei einem taxonomisch und ökologisch mannigfaltigeren Versuchsmaterial diese Lücke auch zeigen oder ob sie sich schliessen wird, ist eine bisher unbeantwortete Frage.

\section{$3.2 U V$-Strahlen}

Die Resultate der UV-Bestrahlung gehen gesamthaft parallel jenen der Gammabestrahlung: Auch hier ertragen Algen von Extremstandorten hohe, Plankter nur niedrige Strahlendosen. Aphanizomenon erwies sich als besonders empfindlich: zweiminütige Bestrahlung tötete alle Zellen ab. Anabaena flos-aquae zeigte gegen UV-Strahlen eine hohe, aus der Reihe der übrigen Plankter herausfallende Resistenz. Der Wachstumsverlauf der UV-bestrahlten Kulturen lässt vermuten, dass vegetative Zellen geringe, Dauerzellen hohe Resistenz zeigen: Subkulturen aus 2, 4, 8 und 16 Minuten lang bestrahltem Material wuchsen sofort an. Dagegen wiesen Subkulturen aus länger bestrahltem Material nach 42 Tagen noch keine makroskopisch sichtbare Entwicklung auf. Diese setzte erst nach fast zweimonatiger Inkubationszeit, dann aber sehr rasch, ein. Vermutlich hatten vereinzelte Dauerzellen die längere Bestrahlungszeit überlebt und keimten mit starker Verzögerung.

Mit einer Ausnahme überlebten bei unserer Versuchsanordnung auch die Begleitbakterien der Algen die höchsten UV-Strahlendosen. Nur Phormidium autumnale wurde so bakterienfrei.

\subsection{Verhalten axenischer Kulturen}

Axenische Subkulturen von Chroococcus minor, Chamaesiphon polonicus, Tolypothrix penicillata und Phormidium autumnale lassen sich von bakterienhaltigen Parallelkulturen der gleichen Klone weder makroskopisch noch bei kursorischer Durchmusterung mikroskopisch unterscheiden. Eingehende Vergleichsanalysen wurden freilich bisher nicht angestellt. 
Axenische Kulturen von Scytonema myochrous erscheinen gelatinöser als bakterienhaltige. Offenbar bauen Bakterien einen Teil des ausgeschiedenen Scheidenmaterials ab.

Einige Monate alte axenische Standkulturen von Scytonema burmanicum riechen widerlich, während unbestrahlte Parallelkulturen mit Begleitbakterien geruchlos sind. Die Erscheinung wiederholt sich in sukzessiven Subkulturen regelmässig. Um zu klären, ob der Geruch auf eine durch die Bestrahlung verursachte Mutation oder auf das Fehlen von Begleitbakterien zurückzuführen sei, wurde folgendes Experiment durchgeführt: Algenmaterial aus einer bakterienhaltigen Stammkultur wurde gleichzeitig in Nährlösung Z, auf Trypton-Glukose-Extrakt-Agar und auf Nährgelatine (Difco) übertragen. Auf den beiden Bakteriennährböden entwickelte sich je ein Gemisch von Bakterien, während in Medium $Z$ der Algenklon samt Begleitbak, terien wuchs. 2 Monate alte axenische, widerlich riechende Algenkulturen wurden in vier Serien geteilt und wie folgt behandelt:

Serie 1: Kontrollen, ohne Behandlung.

Serie 2: Beimpfung mit dem auf Trypton-Glukose-Extrakt-Agar herangewachsenen Bakteriengemisch.

Serie 3: Beimpfung mit dem auf Nährgelatine herangewachsenen Bakteriengemisch.

Serie 4: Beimpfung mit bakterienhaltigem Scytonema burmanicum aus einer Kultur in Medium Z.

Einige Monate nach der Zusatzimpfung sahen alle Kulturen makroskopisch gleich aus, doch rochen die Serien 1,2 und 3 noch gleich widerlich, während Serie 4 geruchlos geworden war. Der auffallende Geruch ist damit wohl nicht das Resultat einer Mutation, sonst wäre sein Verschwinden aus den Kulturen der Serie 4 nicht erklärlich. Offenbar scheidet der vorliegende Scytonemaklon ein stark riechendes Stoffwechselprodukt aus, welches von Begleitbakterien abgebaut wird und damit in bakterienhaltigen Kulturen mit einfachem Riechtest nicht nachzuweisen ist. Die geruchstoffabbauenden Bakterien lassen sich aus den Algenkulturen nicht auf TGE-Agar oder Nährgelatine isolieren, sonst hätten die Kulturen der Serien 2 und/oder 3 nach der Beimpfung mit den Bakterien den Geruch verloren. Es handelt sich offenbar um mehr oder weniger spezifische Begleitbakterien, bei deren Fehlen der Geruchstoffabbau unterbleibt. Versuche, diese Bakterien zu isolieren, wurden bisher nicht unternommen.

Eine analoge Beobachtung wurde bei Scytonema lyngbyoides gemacht: Das Kulturfiltrat mehrmonatiger axenischer Standkulturen ist dunkelgelb bis orange gefärbt und riecht zwar schwach, aber deutlich unangenehm «seifig». Die Algen bilden einen dunkelgrünen Pelz an der Mediumoberfläche. Das Filtrat paralleler, bakterienhaltiger Kulturen ist hellgelb und geruchlos, der Algenpelz blass olivgrün. Wurden solche Kulturen gleich behandelt wie jene von S.burmanicum, so verschwand auch hier eindeutig der seifige Geruch axenischer Kulturen nach zusätzlicher Einimpfung bakterienhaltigen Algenmaterials. Die Wirkung der Zusatzimpfung auf den makroskopischen Habitus der Kulturen und auf die Verfärbung des Mediums war visuell nicht eindeutig fassbar. 


\section{Schlussfolgerungen}

Die geringe Zahl der bestrahlten Taxa erlaubt kaum weitgehende Verallgemeinerungen. Immerhin geben die Resultate einige Hinweise, die aber weiterer experimenteller Prüfung bedürfen:

Die Toleranz von Blaualgen gegenüber kurzwelliger Strahlung hängt nicht mit ihrer taxonomischen Stellung, wohl aber mit ihrem ökologischen Verhalten in der Natur zusammen. So zeigen Plankter nur geringe Resistenz. In ihrem natürlichen Lebensraum werden sie durch die obersten Wasserschichten von jeher gegen intensive kurzwellige Strahlung abgeschirmt. Eine Selektion strahlungsresistenter Mutanten unterblieb deshalb. Dagegen tolerieren an Extremstandorte adaptierte, euryöke Arten hohe Dosen kurzwelliger Strahlen. Diese Arten besiedeln zum Teil wohl seit geologisch weit zurückliegenden Epochen Standorte mit extremem Strahlungsklima. Das führte im Laufe der Zeit zur Selektion strahlungsresistenter Mutanten. So lässt sich die extreme Resistenz etwa von Chamaesiphon polonicus verstehen.

Praktisch ist interessant, dass die Behandlung mit Gammastrahlen bei Aerophyten bzw. Lithophyten mit gelatinösen Scheiden, aus denen Bakterien sonst schwer zu eliminieren sind, eine einfache Methode darstellt, um zu axenischen Kulturen zu gelangen.

\section{Zusammenfassung}

13 Klone von Blaualgen verschiedener taxonomischer Stellung (Chroococcales, Chamaesiphonales, Nostocales) und verschiedener ökologischer Gruppen (Plankter, Litoralformen, Aerophyten schattiger und sonniger Standorte) wurden mit Gammaund UV-Strahlen behandelt. Plankter erwiesen sich unabhängig von ihrer taxonomischen Stellung als wenig widerstandsfähig: Die maximale Gammastrahlentoleranz betrug je nach Klon 65 bis $260 \mathrm{krad}$ bei Bestrahlungszeiten von rund 10 bis 40 Minuten, die maximale UV-Strahlentoleranz belief sich (mit einer Ausnahme) unter unseren Versuchsbedingungen auf eine Bestrahlungszeit von 32 Minuten. Begleitbakterien tolerierten durchwegs höhere Strahlendosen. Dagegen erwiesen sich Aerophyten bzw. Lithophyten von Standorten mit extremem natürlichem Strahlungsklima auch im Experiment als sehr resistent. So überlebten Chamaesiphon polonicus und Scytonema burmanicum siebenstündige Exposition in Gammastrahlen (totale Dosis $2500 \mathrm{krad}$ ) sowie vierstündige UV-Bestrahlung. Begleitbakterien überlebten zwar die UV-Behandlung, nicht aber die hohen Gammastrahlendosen. Behandlung mit Gammastrahlen. eignet sich daher zur Gewinnung axenischer Kulturen von Cyanophyten extremer Naturstandorte.

Mehrere Monate alte axenische Kulturen von Scytonema burmanicum und von S.lyngbyoides riechen übel, während bakterienhaltige Kulturen geruchlos bleiben. Vermutlich bauen die Begleitbakterien von den Algen ausgeschiedene, übelriechende Stoffwechselprodukte zu geruchlosen Verbindungen ab.

\section{SUMMARY}

Thirteen strains of blue-green algae including members of the Chroococcales, Chamaesiphonales and Nostocales and belonging to various ecological groups have been exposed to various doses of gamma and 
UV radiation. Tolerances were independent of the taxonomic position but correlated with the ecological behaviour of the taxa involved. While planktonic species were quite sensitive to both UV and gamma radiation (maximum tolerance in the range of 65 to $260 \mathrm{krad}$ ), aerophytic and lithophytic species tolerated up to more than $2500 \mathrm{krad}$ of gamma radiation and more than 4 hours of exposition to UV radiation. In cultures of planktonic species. gamma radiation killed the algae prior to the associated bacteria so that no axenic cultures could be obtained. In some cultures of aerophytic and lithophytic taxa however, bacteria were killed prior to the algae. Thus, axenic cultures of these strains could be obtained.

Old axenic cultures of Scytonema burmanicum and of S. lynghyoides display a bad smell, whereas cuitures with bacteria are odourless. Probably, the bacteria are reducing to odourless compounds the smelling substances excreted by the algae.

\section{RÉSUMÉ}

Treize souches cloniques de Cyanophycées d'eau douce appartenant aux ordres des Chroococcales, des Chamaesiphonales et des Nostocales et représentant divers types écologiques à savoir des formes du plancton et du littoral ainsi que des espèces saxicoles aériennes, et subaériennes de habitats ombreux et fort ensoleillés ont été traité aux rayons gamma et UV. Les espèces planctoniques se montraient peu résistantes. indépendemment de leur position taxonomique: Dans nos conditions, elles supportaient au maximum 32 minutes d'irradiation de rayons UV. et, selon la souche clonique, de 65 à $260 \mathrm{krad}$ de rayons gamma. Les bactéries acçompagnant les algues supportaient partout des doses d'irradiation plus élevées. Par contre. les espèces saxicoles provenant de stations aériennes ou subaériennes se montraient très résistantes. Chamaesiphon polonicus et Scytonema burmanicum par exemple supportaient dans nos conditions une irradiation UV de 4 heures et une exposition aux rayons gamma de 6 heures (dose totale: $2500 \mathrm{krad}$ ). Les bactéries accompagnant ces espèces supportaient les rayons UV, mais non les rayons gamma. Le traitement avec des rayons gamma peut donc aboutir à des cultures axéniques de Cyanophycées d'habitats aériens ou subaériens.

Les cultures axéniques de Scytonema burmanicum et de S.lyngbyoides âgées de quelques mois sentent mauvais, tandis que les cultures parallèles dont les algues sont accompagnées de bactéries restent sans odeur. Il semble que les bactéries décomposent les substances d'odeur désagréable produites par les deux espèces.

\section{VERDANKUNGEN}

Der Stiftung der Wirtschaft zur Förderung des Gewässerschutzes in der Schweiz sei für die finanzielle Unterstützung dieser Arbeit herzlich gedankt. Herrn Dr. Baertschi, Eidgenössisches Institut für Reaktorforschung. Würenlingen, danken wir für die Berechnung der Expositionszeiten und für die Durchführung der Bestrahlungen mit Gammastrahlen.

\section{LITERATURVERZEICHNIS}

1 Allen, M. B.: The cultivation of Myxophyceae. Arch. Mikrobiol. 17. 34-53 (1952).

2 Allen, M.M.: Simple Conditions for Growth of Unicęllular Blue-Green Algae on Plates. J. Phycol. 4. $1-4(1968)$.

3 Asato, Y.: Photorecovery of Gamma Irradiated Cultures of a Blue-Green Alga, Anacystis nidulans. Radiat. Bot. 11, 313-316 (1971).

4 Carmichael, W.W., und Gorham, P.R.: An Improved Method for Obtaining Axenic Clones of Planktonic Blue-Green Algae. J. Phycol. 10, 238-240 (1974).

5 Castenholz, R.W.: Laboratory Culture of Thermophilic Cyanophytes. Schweiz. Z. Hydrol. 32, 538 $551(1970)$.

6 Desikachari, T. V.: Cyanophyta. I.C.A.R., New Delhi. Academic Press, London 1959.

7 Fogg, G. E.: Studies on Nitrogen Fixation by Blue-Green Algae. I. Nitrogen Fixation by Anabaena cylindrica Lemm. J. exp. Biol. 19, 78-87 (1942).

8 Geitler, L.: Cyanophyceae. In: Rabenhorst's Kryptogamenflora, Bd. 14, S. 1 196. Leipzig 1932. 
9 Gerloff, G.C., Fitzgerald, G.P., und Skoog, F.: The Isolation, Purification and Culture of BlueGreen Algae. Am. J. Bot. 37, 216-218 (1950).

10 Golubić, S.: Algenvegetation der Felsen. In: Die Binnengewässer, Bd.XXIII, S. 183. Stuttgart 1967.

11 Holm-Hansen, O.: Ecology, Physiology, and Biochemistry of Blue-Green Algae. Ann. Rev. Microbiol. 22, 47-70 (1968).

12 Hughes, E.O., Gorham, P.R., und Zehnder, A.: Toxicity of a Unialgal Culture of Microcystis aeruginosa. Can. J. Microbiol. 4, 225-236 (1958).

13 Jaag, O.: Untersuchungen über die Vegetation und Biologie der Algen des nackten Gesteins in den Alpen, im Jura und im Schweizerischen Mittelland. Beitr. Kryptogamenflora Schweiz 9 (3), 1-560. Bern 1945.

14 Kann, E.: Zur Systematik und Ökologie der Gattung Chamaesiphon (Cyanophyceae). 1. Systematik. Arch. Hydrobiol. Suppl 41 (Algological Studies 7), 117-171 (1972).

15 Kann, E.: Zur Systematik und Ökologie der Gattung Chamaesiphon (Cyanophyceae). 2.Ökologie. Arch. Hydrobiol. Suppl. 41 (Algological Studies 8), 243-282 (1973).

16 Kann, E., und Komárek, J.: Systematisch-ökologische Bemerkungen zu den Arten des Formenkreises Phormidium autumnale. Schweiz. Z. Hydrol. 32, 495-518 (1970).

17 Kraus, M.P.: Preparation of Pure Blue-Green Algae. Nature 211, 310 (1966).

18 Lange, W.: Transformation of Nonpolar Filaments of the Blue-Green Alga Gloeotrichia echinulata U. Wisc. 1052 into Double Helices. J. Phycol. 11, 75-79 (1975).

19 Messikommer, E.: Eine neue Planktoninvasion im Pfäffikersee. Vjschr. natf. Ges. Zürich 106, 448449 (1961).

20 Morton, S.D., und Derse, P.D.: Use of Gammaradiation to Control Algae. Envir. Sci. Technol. 2, 1041-1043 (1968).

21 Prescott, G.W.: Algae of the Western Great Lakes Area. Cranbrook Institute of Science, Bull. No.31, S.946. Bloomfield Hills, 1951.

22 Rubenchik, L.I., Bershova, O.I., u. a.: Preparation of Biological Pure Cultures of Some Blue-Green Algae. Hydrobiol. J. 8, 93-96 (1972).

23 Skuja, H.: Zur Süsswasseralgenflora Burmas. Nova Acta R. Soc. Scient. upsal., ser.IV, 14, 1-188 (1949).

24 Stanier, R.Y., Kunisawa, R., Mandel, M., und Cohen-Bazire, G.: Purification and Properties of Unicellular Blue-Green Algae (Order Chroococcales). Bact. Rev. 35, 171-205 (1971).

25 Staub, R.: Ernährungsphysiologisch-autökologische Untersuchungen an der planktischen Blaualge Oscillatoria rubescens DC. Schweiz. Z. Hydrol. 23, 82-198 (1961).

26 Van Baalen, C.: Further Observations on Growth of Single Cells of Coccoid Blue-Green Algae. J. Phycol. 3, 154-157 (1967).

27 Zehnder, A.: 3. Symposium über Fragen der Cyanophytensystematik in Kastanienbaum, 1963. Verhandlungsbericht. Schweiz. Z. Hydrol. 26, 147-164 (1964).

28 Zehnder, A.: 6. Symposium über Fragen der Cyanophytentaxonomie in Kastanienbaum, 3.-16. August 1972. Verhandlungsbericht. Schweiz. Z. Hydrol. 35, 121-135 (1973).

Adressen der Autoren: Dr. Alfons Zehnder, Limnologische Abteilung der EAWAG, CH-8600 Dübendorf - Beatrix Egli, Seenforschungslaboratorium der EAWAG/ETH, CH-6047 Kastanienbaum. 